\title{
Segurança alimentar e nutricional de crianças menores de dois anos de famílias de trabalhadores rurais Sem Terra
}

\author{
Food and nutrition safety of children under two years of age \\ in families of landless rural workers
}

\author{
Regina Maria Ferreira Lang ${ }^{1}$ \\ Cláudia Choma Bettega Almeida ${ }^{1}$ \\ José Augusto de Aguiar Carrazedo Taddei ${ }^{2}$
}

${ }^{1}$ Departamento de Nutrição, Setor de Ciências da Saúde,

Universidade Federal do

Paraná. Rua Lothário

Meissner 3400, Jardim

Botânico. 80210-170

Curitiba PR.

nutmet@terra.com.br

${ }^{2}$ Universidade Federal de

São Paulo.

\begin{abstract}
To date little is known of health, nutrition and food safety conditions of children living in rural camps and settlements. The present crosssectional descriptive study seeks to present and discuss such conditions for children under two years of age in families of landless rural workers in the Central Western region of the State of Paraná. The study was conducted with a total of 337 children under two years of age in families living in two rural settlements and two rural camps. The main variables related with proteinenergy malnutrition were assessed. Results indicated that the prevalence of protein-energy malnutrition was $4.7 \%$ in settlements and $10 \%$ in camps. Home location, home type and the possibility of producing food for private consumption were the distal variables that influenced most the nutritional status of the pediatric population analyzed. This study established that the search for nutritional and food safety must consider the right of accessing resources and proper means to produce safe and healthy foods in order to enable adequate feeding compatible with the habits and practices of the region.
\end{abstract}

Key words Food safety, Rural settlements, Nutritional evaluation, Protein-energy malnutrition
Resumo De modo a conhecer melhor as condições de saúde, de nutrição e de segurança alimentar das crianças que residem em assentamentos $e$ acampamentos rurais, o presente trabalho avaliou menores de dois anos de idade de famílias de trabalhadores rurais Sem Terra, localizados na região centro-oeste do estado do Paraná. Foi conduzido estudo descritivo de delineamento transversal, que considerou como unidade as famílias com crianças nessa faixa etária residentes em dois assentamentos rurais e dois acampamentos rurais, totalizando 337 crianças. A avaliação mostrou que a prevalência de desnutrição energéticoprotéica foi de 4,7\% nos assentamentos e 10,0\% nos acampamentos. As variáveis distais que mais influenciaram o estado nutricional da população pediátrica analisada foram: o local e o tipo de moradia, e a possibilidade de produção de alimentos para auto consumo. Assim, verificou-se que a busca pela Segurança Alimentar e Nutricional tem que passar pelo direito de acesso aos recursos e meios para produzir alimentos seguros $e$ saudáveis que possibilitem uma alimentação condizente com os hábitos e práticas da região.

Palavras-chave Segurança alimentar e nutricional, Assentamentos rurais, Desnutrição energético-proteica 


\section{Introdução}

A alimentação e a nutrição adequadas devem ser compreendidas como um direito humano. Um dos elementos fundamentais que pode assegurar o cumprimento deste direito seria a segurança alimentar e nutricional definida como "a garantia a todos os cidadãos ao acesso contínuo e permanente a alimentos básicos de qualidade e em quantidade suficiente, com base em práticas alimentares saudáveis de modo a contribuir para uma existência digna, em um contexto de desenvolvimento integral da pessoa humana"1.

A insegurança alimentar tem marcado historicamente o perfil alimentar e nutricional da população brasileira, estando vinculada tanto ao recrudescimento das doenças infecciosas e carenciais em algumas regiões, como também ao crescimento de doenças crônicas não-transmissíveis em vários segmentos da população, caracterizando, assim, um dado contraditório e paradoxal da situação nutricional que afeta o Brasil.

No meio rural brasileiro, a dificuldade de acesso ao principal meio de produção agrícola, a terra, contribui para essa situação de insegurança alimentar. De acordo com Ranieri², "a elevada concentração da propriedade da terra no Brasil é um dos principais fatores responsáveis pela expulsão da população rural" para as áreas urbanas. Uma das soluções para esta questão é a implantação de um efetivo programa de reforma agrária via constituição de assentamentos rurais.

De acordo com Sauer", "assentamento é um espaço geograficamente delimitado, que abarca um grupo de famílias beneficiadas por programas governamentais de reforma agrária. A constituição do assentamento é resultado de um decreto administrativo do governo federal que estabelece condições legais de posse e uso da terra”.

Os últimos dados quantitativos referentes ao número de famílias assentadas são datados de 1996 e advém do I Censo da Reforma Agrária, coordenado pelo INCRA - Instituto Nacional de Colonização e Reforma Agrária. Bergamasco ${ }^{4}$ refere que "o censo apurou um total de 161.556 famílias beneficiárias em 1.460 projetos de assentamentos distribuídos por 26 estados da Federação".

O Paraná se caracteriza por um amplo desenvolvimento da agricultura voltada ao agronegócio, altamente intensiva no uso de insumos químicos, na mecanização e na obtenção de altas produtividades. Por outro lado, porém, mantém populações inteiras em situação de insegurança alimentar, muitas vezes causada pela concentra- ção da terra e dos meios de produção, da riqueza e da renda.

De acordo com Dias ${ }^{5}$ o estado apresentava, em 2004 "14.618 famílias assentadas em projetos da reforma agrária e 16.497 famílias acampadas esperando ser assentadas. Cerca de 300.000 hectares de terra foram utilizados para 260 assentamentos de trabalhadores rurais no estado no período de 1985 a 2001".

A região central do estado - Cantuquiriguaçu e adjacências - concentra os maiores índices de pobreza em todo o Paraná. É também onde estão assentadas cerca de 5.000 famílias de agricultores em projetos de reforma agrária, dos quais o mais recente encontra-se em fase de implantação em parte do latifúndio Giacometi $M a-$ rondin, no município de Quedas de Iguaçu, com cerca de quinhentas famílias. Além disso, existem diversos acampamentos de famílias Sem Terra em luta pela posse da terra.

Segundo Caldart, citado por Pires "o Movimento dos Trabalhadores Rurais Sem Terra (MST) nunca utilizou em seu nome nem o hífen, nem o $s$, o que historicamente acabou produzindo um nome próprio, Sem Terra, que é também sinal de uma identidade construída com autonomia. O uso social do nome já alterou a norma referente à flexão de número, sendo hoje já consagrada a expressão os Sem Terra. Quanto ao hífen, fica como distintivo da relação entre esta identidade coletiva de trabalhadores e trabalhadoras da terra e o Movimento que a transformou em nome próprio, e a projeta para além de si mesma". Como Pires, adotamos a expressão Sem Terra para determinar uma identidade auto proclamada, mesmo entre os agricultores assentados e, portanto, já com a posse da terra.

Como parte da estratégia dessas famílias no estágio de luta pela terra, a realização de acampamentos é uma tática empregada por milhares de famílias que não encontram alternativas produtivas e tampouco apoio governamental para uma vida digna e cidadã. Pode-se afirmar que é por meio das ocupações de terra, que os Sem Terra mantêm na pauta política a questão da reforma agrária. Desta forma, podemos afirmar que as ocupações de terra tornaram-se a principal forma de acesso à terra sendo, portanto, uma forma de criação e recriação do campesinato.

Apesar da situação de insegurança alimentar e nutricional em que se encontram grupos populacionais específicos, pouco se conhece sobre a saúde e a nutrição de crianças que residem em assentamentos e acampamentos rurais. Assim, o objetivo do presente trabalho é apresentar e dis- 
Este estudo é parte integrante do Projeto de Pesquisa "Hábitos alimentares, sistemas produtivos agrícolas e insegurança alimentar na região centro-oeste do Paraná", que objetivou realizar diagnóstico referente à segurança alimentar e nutricional em assentamentos e acampamentos rurais.

O presente recorte trata de um estudo descritivo, de delineamento transversal, para o qual se considerou como unidade de estudo as famílias com crianças menores de 24 meses, sendo entrevistadas todas as famílias que atenderam este critério. Em duas famílias existiam duas crianças menores de 24 meses, só a mais jovem foi incluída na amostra.

Assim, definiram-se intencionalmente para amostra os Assentamentos Rurais Ireno Alves dos Santos e 29 de Agosto ( $n=129)$ e os Acampamentos Rurais 10 de Maio - Bacia e José Abúlio dos Santos - Silo $(n=208)$, totalizando 337 famílias.

O Projeto de Assentamento Ireno Alves dos Santos, criado em 1997, na cidade de Rio Bonito do Iguaçu, possui 934 lotes, tendo cada um deles em média 12,40 hectares, dependendo da topografia e da condição do solo, totalizando 16.852,16 hectares.

Já, o Projeto de Assentamento 29 de Agosto possui 80 lotes, tendo cada um deles entre 24 e 31 hectares, também dependendo da topografia e da condição do solo, totalizando 2.216 hectares. Foi criado em 1994 na cidade de Goioxim, região central do Paraná.

O Acampamento do MST 10 de Maio, conhecido como Bacia, foi formado em 1999 a partir da ocupação de terras do latifúndio Giacomet Marodin localizado no município de Quedas do Iguaçu, região oeste do Paraná. No ano de 2003, na mesma área ocorreu uma expansão da área ocupada formando o Acampamento José Abílio dos Santos, conhecido como Silo.

O instrumento de coleta de dados explorou questões sobre condições sócio-demográficas e sanitárias, condiçõoes de saúde da mulher e da criança e utilização dos serviços pelas famílias entrevistadas.

Realizou-se estudo-piloto com o instrumento sendo pré-testado em 20 famílias do Acampamento 10 de Maio - Bacia durante o treinamento das equipes de campo que foi formada por

cinco duplas compostas por um nutricionista ou estudante de nutrição e um agrônomo ou técnico agrícola, estes vinculados ao MST e com conhecimento da região estudada.

A coleta de dados foi realizada no período de 29 de novembro a 6 de dezembro de 2004 no Assentamento 29 de Agosto e em três etapas no Assentamento Ireno Alves dos Santos: 18 a 20 de janeiro, 22 a 25 de fevereiro e 18 a 20 de março de 2005.

Nos Acampamentos 10 de Maio - Bacia e José Abílio dos Santos - Silo a coleta foi realizada nos períodos de 22 a 25 de fevereiro e 18 a 20 de março de 2005.

As dificuldades de locomoção dentro dos Assentamentos e de acesso e localização dos domicílios, bem como a falta de infra-estrutura para a permanência em campo nos Acampamentos, fizeram com que os pesquisadores visitassem os locais em distintas datas, por vários dias e meses, o que explica o longo período de coleta de dados. Estas dificuldades também foram relatadas por outros autores em estudo realizado em um assentamento rural do estado do Rio de Janeiro ${ }^{7}$.

A avaliação antropométrica foi realizada no momento da entrevista por uma equipe de seis entrevistadores composta por professores e alunos do curso de Nutrição da UFPR, previamente treinada e as medidas tomadas, atenderam às recomendações do Ministério da Saúde ${ }^{8}$. Em comunidades, a antropometria pode ser considerada um importante instrumento epidemiológico, fornecendo uma estimativa da prevalência e gravidade das alterações nutricionais e se traduzindo em um reflexo biológico da situação de insegurança alimentar e nutricional.

As medições foram realizadas em duas tomadas e obedeceram aos procedimentos descritos a seguir:

Para a coleta de peso das crianças foi utilizada balança marca SECA, com capacidade de $150 \mathrm{~kg}$, com escala de 100 gramas. As crianças foram pesadas no colo da mãe ou responsável, com indumentária mínima, na balança previamente zerada.

O comprimento foi medido no mesmo momento da pesagem. As crianças foram medidas em decúbito dorsal em uma superfície plana, com um infantômetro confeccionado em barra de madeira, amplitude de $100 \mathrm{~cm}$ e subdivisões de $0,1 \mathrm{~cm}$.

As leituras de peso e comprimento foram repassadas pelo entrevistador em voz alta e registradas no instrumento por outro entrevistador.

Os questionários foram avaliados quanto à sua consistência, antes de serem liberados para a 
digitação. As informações foram transcritas em banco de dados com dupla digitação no pacote Epi Info 6.04.

O ponto de corte para caracterização da desnutrição foi o escore $-Z \mathfrak{E}-2$ tanto para o índice peso/idade, que se definiu como Desnutrição Energético-Proteica (DEP) quanto para o índice altura/idade que classificou a Desnutrição Energético-Proteica Crônica (DEP-C), como para o índice peso/altura que se classificou de Desnutrição Energética Proteica Atual (DEP-A) conforme proposição da Organização Mundial de Saúde 9 .

Procurando contextualizar a situação nutricional, avaliaram-se as condições sócio-demográficas e sanitárias, as condições de saúde da mulher e da criança e a utilização dos serviços pelas famílias entrevistadas relacionadas com a desnutrição. Todas estas variáveis foram dicotomizadas, sendo o critério de categorização a presença ou ausência do fator ou o valor da mediana apresentada pela variável na amostra estudada.

\section{Resultados e discussão}

Os resultados apontaram que, das 337 crianças avaliadas, 129 (38,3\%) pertenciam a famílias de trabalhadores rurais Sem Terra assentadas, ou seja, que já possuem a posse da terra e 208 $(61,7 \%)$ eram de famílias acampadas, ou seja, viviam em áreas ocupadas pelo MST em estágio anterior da luta pela terra.

Do total da população pediátrica analisada, 8,0\% apresentaram déficits nos índices peso/idade e altura/idade, ou seja, possuíam DEP e DEP$\mathrm{C}$ no momento da pesquisa. Castro ${ }^{10}$, em estudo com crianças assentadas em Minas Gerais, encontrou 7,6\% de casos de DEP em crianças menores de 60 meses. Em outra região mineira, Juiz de Fora, encontrou um percentual de 10,62 para DEP e 11,23 para DEP-C.

A Tabela 1 apresenta as prevalências de DEP e DEP-C na amostra infantil avaliada de acordo com características de habitação, condições sanitárias da habitação, acesso a bens de consumo e serviços, características maternas e das crianças.

Quando se efetuou a avaliação da situação nutricional em relação ao local de moradia, verificou-se que a DEP e DEP-C entre os acampados alcançou índice de 10,0\% contra 4,7\% para as crianças filhas de trabalhadores rurais assentados, apontando que a situação de maior risco de insegurança alimentar e nutricional foi encontrada entre as famílias sem a posse da terra. Acredita-se que a posse da terra por si só não é o único fator determinante da situação nutricional, mas a segurança de ter seu espaço para plantar, colher e comer é, sem dúvida, colaborador para a garantia da saúde e nutrição destas famílias.

Em relação às características das habitações verificou-se, ainda, que as variáveis "tipo de moradia" e "número de cômodos da casa" quando avaliadas as prevalências de DEP e DEP-C apresentaram índices de $13,7 \%$ e $12,7 \%$ respectivamente, nos acampamentos e de $5,6 \%$ e $6,0 \%$ nos assentamentos.

Destacam-se as condições de insalubridade que as barracas de lona plástica, proporcionam aos seus ocupantes, pois este tipo de moradia expunha principalmente as crianças, às variações climáticas ao longo do dia, da noite e das estações do ano. Viver "embaixo da lona", como os Sem Terra falam, é morar num ambiente abafado no dias de calor e frio e úmido nos dias de inverno, fatores sanitários determinantes de agravos de saúde, principalmente entre lactentes, como são as infecções respiratórias agudas, podendo levar a agravamentos da situação nutricional.

$\mathrm{Na}$ análise do acesso aos bens de consumo pelas famílias observou-se que as crianças cujas famílias possuíam freezer e fogão a gás apresentaram menores índices de desnutrição, tanto para DEP quanto para DEP-C. A ausência de geladeira na residência mostrou-se significativa na gênese da desnutrição crônica com índice de 10,8\% para as crianças de famílias que não apresentam este bem. Destes dados pode-se inferir que a posse de determinados bens pela família contribui para que a situação nutricional apresente-se melhorada. A geladeira, em especial, constitui-se em equipamento indispensável para a conservação e conseqüente armazenagem de alimentos, principalmente os perecíveis, indispensáveis para a boa nutrição infantil. Vale ressaltar, no entanto, que das 337 famílias avaliadas, apenas 152 (45,1\%) possuíam geladeira contra $185(54,9)$ que não possuíam este bem no momento da pesquisa, situação que se corrigida pode contribuir para a melhoria das condições nutricionais infantis.

Quando se avaliou o acesso a serviços, verificou-se que a mediana da distância ao serviço se saúde mais próximo à residência foi de 9 quilômetros. Distâncias maiores que este valor apontam prevalência de DEP de 9,3\% e prevalência de DEP-C de 9,9\%. Dentre os equipamentos de saúde utilizados pelos entrevistados, os mais citados foram a unidade de saúde municipal e o hospital municipal de Rio Bonito do Iguaçu. Kassouf ${ }^{11}$, em estudo que analisou o acesso aos serviços de saúde nas áreas rurais do Brasil, a partir de da- 
Tabela 1. Prevalências de Desnutrição Energético Proteica - DEP (P/I E - 2Z) e Desnutrição Energético Proteica Crônica - DEP-C (E/I E - 2 Z) em crianças menores de dois anos de famílias de trabalhadores rurais Sem Terra, de acordo com características de habitação, condições sanitárias da habitação, acesso a bens de consumo e serviços, características maternas e das crianças. Paraná, 2005.

\begin{tabular}{|c|c|c|c|c|c|}
\hline \multirow{2}{*}{$\begin{array}{c}\text { Variáveis } \\
\text { Características da habitação }\end{array}$} & \multirow[t]{2}{*}{ Descrição } & \multicolumn{2}{|c|}{$\begin{array}{c}\text { Prevalência de } \\
\text { DEP e valor de } p\end{array}$} & \multicolumn{2}{|c|}{$\begin{array}{c}\text { Prevalência de } \\
\text { DEP-C e valor de p }\end{array}$} \\
\hline & & & & & \\
\hline \multirow[t]{2}{*}{ Local de moradia } & Acampamento & 10,0 & 0,039 & 10,0 & 0,039 \\
\hline & Assentamento & 4,7 & & 4,7 & \\
\hline \multirow[t]{2}{*}{ Tipo de moradia } & Barraco de lona & 13,7 & 0,005 & 12,7 & 0,018 \\
\hline & Casa madeira/tijolo & 5,6 & & 6,0 & \\
\hline \multirow[t]{2}{*}{ Número de cômodos } & Até dois cômodos & 10,3 & 0,055 & 8,6 & 0,347 \\
\hline & Mais de três & 5,6 & & 7,4 & \\
\hline \multicolumn{6}{|l|}{ Condições sanitárias da habitação } \\
\hline \multirow[t]{2}{*}{ Local do banheiro } & Dentro de casa & 3,2 & 0,058 & 7,9 & 0,490 \\
\hline & Fora de casa & 9,1 & & 8,0 & \\
\hline \multicolumn{6}{|c|}{ Acesso a bens de consumo pela família } \\
\hline \multirow[t]{2}{*}{ Geladeira } & Sim & 7,2 & 0,317 & 4,6 & 0,018 \\
\hline & Não & 8,6 & & 10,8 & \\
\hline \multirow[t]{2}{*}{ Freezer } & Sim & 5,2 & 0,148 & 2,6 & 0,022 \\
\hline & Não & 8,9 & & 9,7 & \\
\hline \multirow[t]{2}{*}{ Fogão à gás } & Sim & 5,9 & 0,040 & 7,4 & 0,302 \\
\hline & Não & 11,2 & & 9,0 & \\
\hline \multicolumn{6}{|l|}{ Acesso a serviços } \\
\hline \multirow[t]{2}{*}{ Distância serviço de saúde } & Maior que $9 \mathrm{~km}$ & 9,3 & 0,186 & 9,9 & 0,098 \\
\hline & Até $9 \mathrm{~km}$ & 6,7 & & 6,1 & \\
\hline \multirow[t]{2}{*}{ Recebe visita do ACS } & Sim & 10,7 & 0,095 & 8,2 & 0,095 \\
\hline & Não & 6,5 & & 8,1 & \\
\hline \multicolumn{6}{|l|}{ Características das crianças } \\
\hline \multirow{2}{*}{ Peso ao nascer } & $<2.500 \mathrm{~g}$ & 25,0 & 0,00003 & 25,0 & 0,00003 \\
\hline & $>2.500 \mathrm{~g}$ & 6,0 & & 6,0 & \\
\hline \multirow[t]{2}{*}{ Faixa etária } & 12 meses & 5,0 & 0,006 & 5,0 & 0,006 \\
\hline & $\geq 12$ meses & 12,5 & & 12,5 & \\
\hline \multirow[t]{2}{*}{ Aleitamento materno } & Sim & 8,0 & 0,097 & 6,3 & 0,037 \\
\hline & Não & 8,3 & & 11,9 & \\
\hline \multicolumn{6}{|l|}{ Produção para autoconsumo } \\
\hline \multirow[t]{2}{*}{ Criação de animais } & Não & 14,4 & 0,009 & 13,3 & 0,003 \\
\hline & Sim & 5,7 & & 6,1 & \\
\hline \multirow[t]{2}{*}{ Possui gado de corte (carne) } & Não & 9,5 & 0.005 & 9,5 & 0,005 \\
\hline & Sim & 2,7 & & 2,7 & \\
\hline \multirow[t]{2}{*}{ Possui gado leiteiro } & Não & 10,1 & 0,006 & 10,6 & 0,002 \\
\hline & Sim & 4,6 & & 3,8 & \\
\hline \multirow[t]{2}{*}{ Possui galinha de corte } & Não & 11,5 & 0,007 & 10,7 & 0,017 \\
\hline & Sim & 6,0 & & 6,0 & \\
\hline \multirow[t]{2}{*}{ Possui produção de ovos } & Não & 10,7 & 0,008 & 9,4 & 0,036 \\
\hline & Sim & 5,6 & & 6,4 & \\
\hline
\end{tabular}

dos da Pesquisa Nacional por Amostra de Domicílios (PNAD), realizada em 1998, verificou que postos ou centros de saúde são os equipamentos mais procurados pela população rural, totalizando $43,2 \%$, seguido dos equipamentos hospitalares, com $26,4 \%$.
A disponibilidade de acesso aos serviços de saúde pode contribuir para a qualidade de vida das crianças assentadas e acampadas, refletindo em sua situação nutricional. Veiga e Burlandy ${ }^{7}$, em pesquisa realizada em assentamento localizado no estado do Rio de janeiro, verificaram 
que $47,8 \%$ da população avaliada referiram a busca por algum tipo de atendimento em serviços de saúde nos três primeiros meses que antecederam o estudo.

Apenas 185 (54,9\%) das famílias analisadas relataram receber a visita do agente comunitário de saúde (ACS) e, das famílias que recebem a visita deste profissional, 10,7\% das crianças apresentavam DEP e 8,2\%, DEP-C. Estes dados apontam que, provavelmente, ocorre uma priorização dos casos de desnutrição nas visitas realizadas pelos ACS. No entanto, vale ressaltar que 6,7\% das crianças que não recebem o acompanhamento pelo ACS também apresentaram DEP.

Dentre as características das crianças avaliadas, o baixo peso ao nascer - peso inferior a $2.500 \mathrm{~g}$ - demonstrou ser significante na gênese da desnutrição, sendo que $25 \%$ das crianças que nasceram com baixo peso apresentaram déficits de altura e de peso para a idade, contra $6,0 \%$ de déficits entre as crianças que nasceram com peso suficiente ou adequado - peso superior a $2.500 \mathrm{~g}$. Castro $^{10}$ também inferiu uma associação entre baixo peso ao nascer e desnutrição.

Como já afirmado no presente texto, no meio rural, o acesso à terra pode resultar em melhores níveis de segurança alimentar pela possibilidade de produção de alimentos para auto consumo. Verificou-se que as famílias que possuíam horta casei- ra e criação de animais para auto consumo apresentaram menores índices de desnutrição. Diferentes autores ${ }^{12-15}$ defendem que a produção para o auto consumo contribui para a melhoria da qualidade de vida, constituindo-se em renda interna, potencializando a renda monetária disponível.

Norder"13 afirma que "parte dos gêneros alimentícios auto consumidos são produzidos sem finalidade comercial e se destina a reduzir o gasto monetário da família com alimentação, ou ainda, a ampliação de sua qualidade”. No presente estudo, esta questão ficou evidente quando se verificou que nas famílias que possuíam gado de corte ou leiteiro, galinhas de corte ou para produção de ovos, a prevalência de DEP e DEP-C foi muito inferior quando comparada com as famílias que não possuíam a criação de animais para consumo.

Quando comparados os resultados encontrados na presente pesquisa com outros estudos realizados em populações infantis igualmente em situação de insegurança alimentar, (Gráfico 01) verificou-se que as prevalências estimadas dos déficits nutricionais DEP, DEP-C e DEP-A entre as famílias de trabalhadores rurais Sem Terra estudadas assemelham-se às situações encontradas entre as populações remanescentes de quilombos ${ }^{16}$, em pesquisa realizada em 2006 durante a campanha de vacinação, com 60 comunidades quilombolas de todo o país.

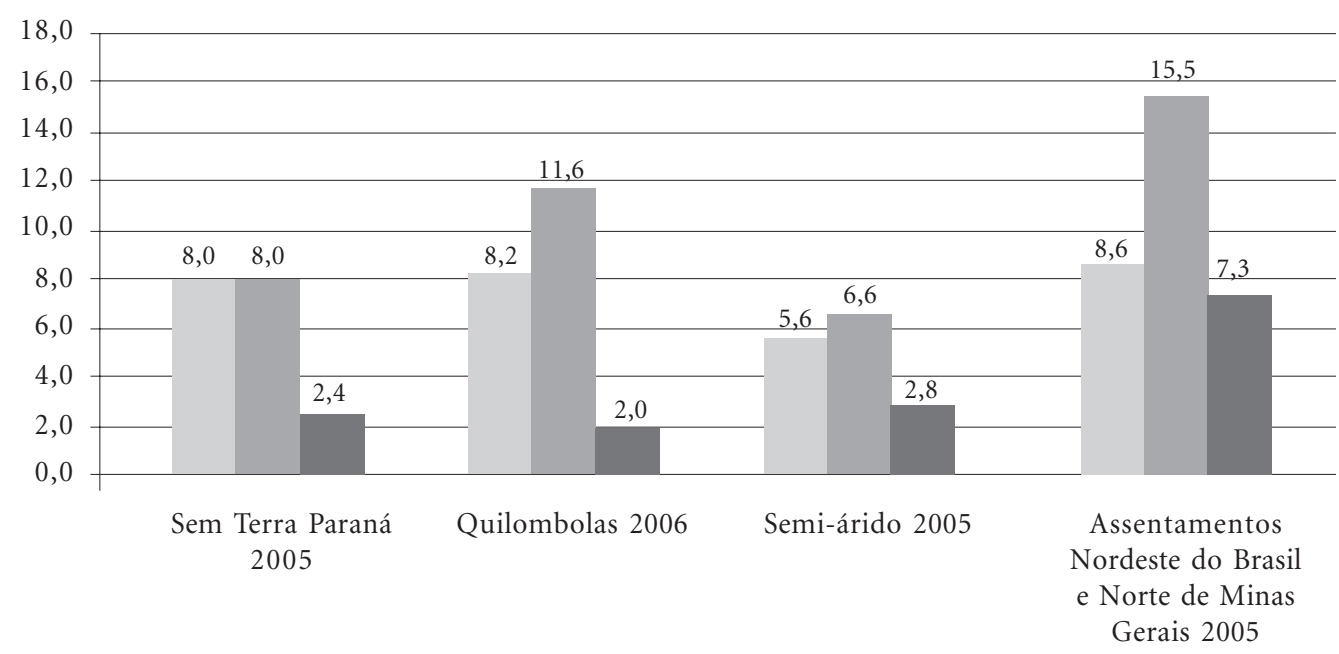

$\square$ DEP $\square$ DEP-C DEP-A

Gráfico 1. Prevalências estimadas dos déficits nutricionais entre as famílias de trabalhadores rurais Sem Terra estudadas e outras populações infantis em situação de insegurança alimentar. 
Pesquisa realizada com o objetivo de avaliar a situação nutricional das crianças do semi-árido brasileiro ${ }^{17}$ apontou freqüências inferiores às aferidas na presente pesquisa tanto para DEP como para DEP-C.

$\mathrm{Na}$ comparação dos dados da presente pesquisa com os resultados de inquérito realizado em assentamentos rurais do Nordeste do Brasil e do norte do estado de Minas Gerais ${ }^{18}$ observou-se um valor muito elevado naquelas comunidades para a DEP-C, 15,7\% em relação aos 8,0\% verificados na presente população.

\section{Considerações finais}

Os resultados sugerem a necessária superação da situação de Insegurança Alimentar com base em práticas sustentáveis. A partir do diagnóstico referente à situação de saúde e nutrição verificou-se que o perfil nutricional das crianças menores de dois anos evidencia freqüência signifi- cativa de eutrofia, mas com preocupantes índices de desnutrição. Acrescenta-se a esta situação as precárias condições das habitações, como o acesso e o tratamento da água para consumo, o esgotamento sanitário, em todos os locais investigados, além das condições de insalubridade que as barracas de lona, como forma de moradia, proporcionam aos seus ocupantes, em especial às lactantes.

Assim, o presente recorte do estudo demonstrou que as variáveis distais ou sócio-econômicas se mostraram mais relevantes em relação às variáveis proximais ou biológicas. Esta consideração contribui para a discussão da segurança alimentar e nutricional demonstrando que o seu conceito vai além da discussão da qualidade e quantidade de alimentos consumidos, mas inclui o direito de acesso aos recursos e meios para produzir estes alimentos, visando o consumo e geração de renda, atingindo condições dignas de vida, como já indicado em ensaio produzido por Freitas e Pena ${ }^{19}$.

\section{Colaboradores}

RMF Lang participou do delineamento do estudo, coleta de dados, concepção e redação do artigo; CCB Almeida participou do delineamento do estudo e coleta de dados; JAAC Taddei participou da concepção e redação do artigo. 


\section{Referências}

1. Conselho Nacional de Segurança Alimentar e Nutricional (Consea). Princípios e diretrizes de uma política de segurança alimentar e nutricional. Brasília: CONSEA; 2004.

2. Ranieri SBL. Retrospecto da reforma agrária no mundo e no Brasil. In: Saporovek G, organizador. A qualidade dos assentamentos da reforma agrária brasileira. São Paulo: Páginas e Letras Editora Gráfica; 2003. p. 5-38.

3. Sauer S. O significado dos assentamentos de reforma agrária no Brasil. In: Ministério do Desenvolvimento Agrário. Núcleo de Estudos Agrários e Desenvolvimento Rural (NEAD), organizadores. Assentamentos em debate. Brasília: NEAD; 2005. p. 57-74.

4. Bergamasco SMP. A realidade dos assentamentos rurais por detrás dos números. Estudos Avançados 1997; 11(31):37-49.

5. Dias AC. Reforma agrária e educação. Análise Conjuntural IPARDES 2006; 28(11-12):13-16.

6. Pires LM. O fruto proibido e o pão: um estudo etnográfico no assentamento do Contestado no Paraná. [tese]. São Paulo: Pontifícia Universidade Católica de São Paulo; 2003.

7. Veiga GV, Burlandy L. Indicadores sócio-econômicos, demográficos e estado nutricional de crianças e adolescentes residentes em um assentamento rural do Rio de Janeiro. Cad Saude Publica 2001; 17(6):1465-72.

8. Brasil. Ministério da Saúde. Vigilância alimentar e nutricional (Sisvan): orientações básicas para a coleta, processamento, análise de dados e informação em serviços de saúde. Brasília: Ministério da Saúde/SAS/ DAB; 2004.

9. World Health Organization. Physical status: the use and interpretation of anthropomery. Technical Report Series 854. Geneva: WHO; 1995.

10. Castro TG, Campos F, Priore S, Coelho F, Campos S, Franceschini S, Rangel AA. Saúde e nutrição de crianças de 0 a 60 meses de um assentamento de reforma agrária, Vale do Rio Doce, MG, Brasil. Rev Nutr 2004; 17(2):167-176.

11. Kassouf AL. Acesso aos serviços de saúde nas áreas urbanas e rural do Brasil. RER 2005; 43(1):29-44.
12. Cunha LH, Gomes RA, Menezes MA, Malagodi EA, Ieno Neto G. A construção de índices como instrumentos para retratar a realidade social: uma análise crítica. In: Ministério do Desenvolvimento Agrário. Núcleo de Estudos Agrários e Desenvolvimento Rural (NEAD), organizadores. Assentamentos em Debate. Brasília: NEAD; 2005. p. 40-56.

13. Norder LAC. A construção da segurança alimentar em assentamentos rurais: questões, conexões e métodos. Cadernos de Debate 1998; 6(1):1-18.

14. Santos AC, Biolchi MA, Angelis T. Auto consumo, desenvolvimento e agricultura familiar. Boletim do DESER 2006; 153:22-31.

15. Ferreira HS, Albuquerque MFM, Ataíde TR, Morais MCR, Siqueira TC, Silva GJ. Estado nutricional de crianças menores de dez anos residentes em invasão do "Movimento dos Sem-Terra", Porto Calvo, Alagoas. Cad Saúde Pública 1997; 13(1):137-139.

16. Brasil. Ministério do Desenvolvimento Social e Combate a Fome (MDS)/Secretaria de Avaliação e Gestão da Informação, organizadores. Chamada nutricional Quilombola 2006: resumo executivo. Brasília: MDS; 2007.

17. Monteiro CA, Conde WL, Konno SC. Análise do inquérito chamada nutricional 2005. Cadernos de Estudos Desenvolvimento Social em Debate 2006; 4: 29-36.

18. Tonial SR, Frota MTB. Análise do diagnóstico nutricional nos assentamentos rurais do nordeste e norte de Minas Gerais. Cadernos de Estudos Desenvolvimento Social em Debate 2006; 4:107-114.

19. Freitas MC, Pena PGL. Segurança alimentar e nutricional: a produção do conhecimento com ênfase nos aspectos da cultura. Rev Nutr 2004; 20(1):6981.

Artigo apresentado em 30/07/2008

Aprovado em 13/01/2009

Versão final apresentada em 31/01/2009 